\title{
GASTROENTEROLOGY
}

\section{Abnormal gastroesophageal flap valve is highly associated with gastroesophageal reflux disease among subjects undergoing routine endoscopy in Taiwan}

\author{
BOR-RU LIN, ${ }^{\star}, \dagger$ JAU-MIN WONG,${ }^{\dagger}$ MEI-CHI CHANG,${ }^{\star}$ CHIEN-CHUNG LIAO, ${ }^{\S}$ \\ PEI-MING YANG,${ }^{\dagger}$ JIIANG-HUEI JENG, ${ }^{\natural}$ WAN-RU LIAO ${ }^{\star \star}$ AND TEH-HONG WANG ${ }^{\dagger}$
}

${ }^{\star}$ Division of Endoscopy, Department of Integrated Diagnostics $\mathcal{E}$ Therapeutics, ${ }^{\dagger}$ Division of Gastroenterology, Department of Internal Medicine, National Taiwan University Hospital and National Taiwan University, College of Medicine, Taipei, ${ }^{\ddagger}$ Biomedical Science Team, Chang-Gung Institute of Technology, Taoyuan, ${ }^{\circledR}$ Division of Gastroenterology, Department of Internal Medicine, Cathay General Hospital, Taipei, Departments of ${ }^{\llbracket}$ Dentistry and ${ }^{\star \star}$ Nursing, National Taiwan University Hospital and National Taiwan University, College of Medicine,

Taipei, Taiwan

\begin{abstract}
Objective: Gastroesophageal flap valve (GEFV) grade predicts severe gastroesophageal reflux disease in Caucasians, but its role in other populations is unclear. This study evaluated the significance of endoscopic grading of the GEFV in Taiwanese subjects.

Methods: Five hundred and six consecutive patients undergoing routine check-ups at the National Taiwan University Hospital were enrolled. Symptoms of upper gastrointestinal disease and endoscopic severity of esophageal mucosal injury were correlated to GEFV grades according to the Hill classification.

Results: The frequency of abnormal valves (Hill grades III or IV) was $27.3 \%$. Of these, $42.7 \%$ had erosive esophagitis (EE). The majority of patients with EE were classified as Los Angeles grades A and B (79.7 and $16.9 \%$, respectively). The prevalence of EE, hiatal hernia and, to a lesser degree, non-erosive reflux disease, increased with altered GEFV. Patients with abnormal valves were younger and more likely to be male, overweight, and to have atypical and extraesophageal symptoms.

Conclusions: Taiwanese patients with abnormal GEFVs share similar characteristics and risk factors with the patients who have EE. Endoscopic grading of the GEFV is highly associated with GERD, and in particular EE, in subjects undergoing routine endoscopy.

(C) 2005 Blackwell Publishing Asia Pty Ltd
\end{abstract}

Key words: endoscopy, erosive esophagitis, gastroesophageal flap valve, gastroesophageal reflux disease.

\section{INTRODUCTION}

Evidence of a flap valve at the gastroesophageal junction was first noted in cadavers. ${ }^{1}$ Hill et al. later demonstrated that a gradient is present across the gastroesophageal valve in the absence of hiatal hernia. Loss of this flap valve is associated with the deterioration of lower esophageal sphincter length and pressure, increasing the likelihood of a mechanically defective sphincter. Moreover, the gradient can be increased by surgically accentuating the valve. ${ }^{2}$ The clinical importance of the gastroesophageal flap valve (GEFV) is reflected in the fact that esophageal acid exposure increases proportionately to the degree of valve dysfunction. ${ }^{2-4}$ It has been speculated that reinforcement of the GEFV is achievable by endoluminal gastroplication using endoscopic suturing as therapy for gastroesophageal reflux disease ${ }^{5}$ this endotherapy reinforced valve is comparable to a grade I valve achieved by Nissen fundoplication. ${ }^{6,7}$ Valve grade has been found to predict gastroesophageal reflux better than measured lower esophageal sphincter pressure. $^{2}$ An endoscopic grading system to assess the 
GEFV is a simple and reproducible predictor of gastroesophageal reflux disease (GERD).$^{2-4}$

Few published studies have addressed the relationship of esophagitis to GEFV grade..$^{2-4,8}$ In all but one study, ${ }^{8}$ patients have been symptomatic or had severe esophagitis. The relationship of GEFV grade with GERD is not well examined in non-Caucasian populations. We hypothesized that GEFV grade is associated with the severity of erosive esophagitis (EE) and conducted a prospective study in subjects undergoing routine endoscopy.

\section{PATIENTS AND METHODS}

\section{Subjects}

From July to November 2002, 506 consecutive patients visiting the National Taiwan University Hospital for a health check-up received a panendoscopy and completed a self-administered questionnaire regarding GERD symptoms.

\section{Symptom evaluation}

One day prior to the panendoscopy, patients filled out a self-administered questionnaire regarding the presence and frequency of typical symptoms of GERD (heartburn and acid regurgitation), atypical symptoms, and extraesophageal symptoms. ${ }^{9}$ The frequency of typical symptoms (heartburn and/or acid regurgitation) in the current month was the basis for classification into three groups: (i) one or more times per week; (ii) less than once per week, but more than once per month; or (iii) previous symptoms, but none during the current month. The current symptoms of the remaining patients were the basis for classification into four other groups: (iv) atypical symptoms, including epigastric burning, chest pain or discomfort, food regurgitation, dysphagia and odynophagia; (v) extraesophageal symptoms, including globus sensation over throat and neck, sore throat, hoarseness, chronic cough and asthma; (vi) simultaneous atypical and extraesophageal symptoms; and (vii) lack of any symptoms in groups IV through VI.

\section{Panendoscopic examination and classification of esophageal mucosal injury}

Flexible video endoscopy was performed in each patient under premedication with intramuscular injection of $20 \mathrm{mg}$ of hyoscine butylbromide and topical anesthesia of the pharynx with xylocaine gel. The lower esophagus, squamocolumnar junction, gastroesophageal junction, and diaphragmatic hiatus were thoroughly inspected under adequate endoscopic inflation to maintain optimal visualization without overinflation or masking due to tight tonic contraction of the lower esophageal sphincter. ${ }^{10,11}$ The presence and degree of esophageal mucosal injury were graded according to the Los Angeles classification. ${ }^{12}$ Patients with findings of non-specific changes (e.g. friability, edema, granularity, congestion, erythema or hyperemia) were excluded. ${ }^{13}$ Patients with an isolated salmon-colored mucosal island in their lower esophagus and no squamocolumnar junction involvement were also excluded.

Patients were classified into four groups on the basis of upper endoscopic findings: erosive esophagitis (EE); minute esophagitis (ME) signifying minimal change at the gastroesophageal junction, but absence of typical symptoms such as dyspepsia; non-erosive reflux disease (NERD), signifying normal endoscopy but typical symptoms (symptomatic GERD); ${ }^{14}$ or no esophagitis (NE), signifying normal endoscopy and absent symptoms. GERD was defined as EE plus NERD. Hiatal hernia $(\mathrm{HH})$ was defined as a circular extension of the gastric mucosa above the diaphragmatic hiatus greater than $2 \mathrm{~cm}$ in axial length.

Panendoscopy was performed by an experienced endoscopist, and photographs were reviewed retrospectively by a second endoscopist.

\section{Classification of the gastroesophageal flap valve}

The GEFV was inspected with a retroflexed endoscope and graded I to IV according to the Hill classification as follows: ${ }^{2}$ grade I, prominent fold of tissue along the lesser curvature closely apposed to the endoscope; grade II, fold present, but slightly less well defined than in grade I and it opens rarely with respiration and closes promptly; (i) an incomplete fold; (ii) a non-contact fold remote to the endoscope; grade III, fold not prominent; the endoscope was not gripped tightly by the tissues and often failed to close around the endoscope; grade IV, fold absent with the lumen of the esophagus gaping open, allowing squamous epithelium to be viewed from below. Grades I and II were classified as normal valves and grades III and IV as abnormal valves (Figs 1-4).

\section{Statistical analysis}

The prevalence rates of $\mathrm{EE}$ and hiatal hernia and the frequency of abnormal GEFV were calculated. Age, male to female ratio, body mass index (BMI), presence of hiatal hernia, and symptom category were compared between groups with normal and abnormal grades of GEFV, using unpaired $t$-tests. The chi-squared test with a $4 \times 2$ table and multiple comparative test were performed to evaluate normal and abnormal grades of GEFV among the four groups with esophageal mucosal injury or symptoms. A $P$ value $<0.05$ was considered to be statistically significant.

\section{RESULTS}

The prevalence rates of GERD and EE were $41.3 \%$ $(n=209)$ and $24.7 \%(n=125)$, respectively. As shown in Table 1, more than one-quarter of patients had abnormal valves. Approximately $5 \%$ of patients were 
classified as having grade IV valves. Patients with abnormal valves were significantly younger than those with normal valves. Male patients had a significantly higher prevalence of abnormal valves than female patients, and the prevalence correlated linearly to increasing valve grade. Similarly, BMI correlated linearly with increasing grade of GEFV.

Patient distribution into the above four classifications were: $\operatorname{EE}(n=125 ; 24.7 \%), \operatorname{ME}(n=43 ; 8.5 \%)$, NERD $(n=84 ; 16.6 \%)$, and NE $(n=254 ; 50.2 \%)$. A much greater proportion of patients with EE had abnormal valves than did those with $\mathrm{NE}$ (47.2 vs $15.8 \%$, $P<0.05)$. The proportions of patients with EE according to Los Angeles classification A to D were $72.8 \%$ $(n=91), 24.8 \% \quad(n=31), 1.6 \% \quad(n=2)$ and $0.8 \%$ $(n=1)$, respectively. The ratio of abnormal to normal valves increased in a linear fashion in association with $\mathrm{NE}, \mathrm{NERD}, \mathrm{ME}$ and EE, with the highest prevalence of abnormal valves in the patients with $\mathrm{EE}$.

Table 2 shows that the prevalence of EE increased with increasing valve grade; similarly, a lesser degree was in that of NERD. The prevalence of EE was markedly higher in patients with abnormal valves than in

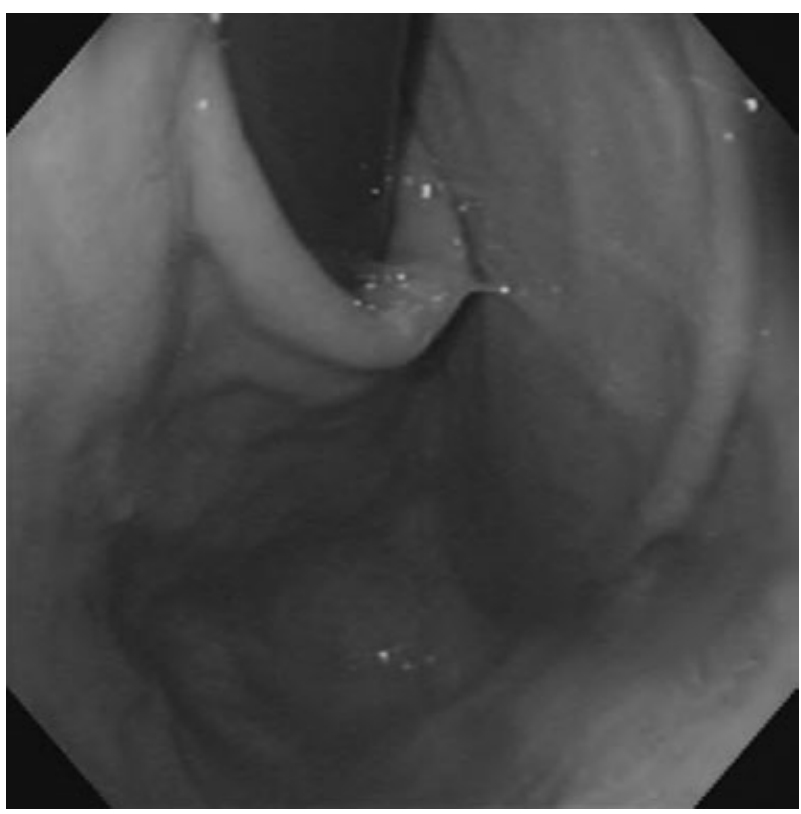

Figure 1 Grade I signified a prominent fold of tissue along the lesser curvature that was closely apposed to the endoscope.
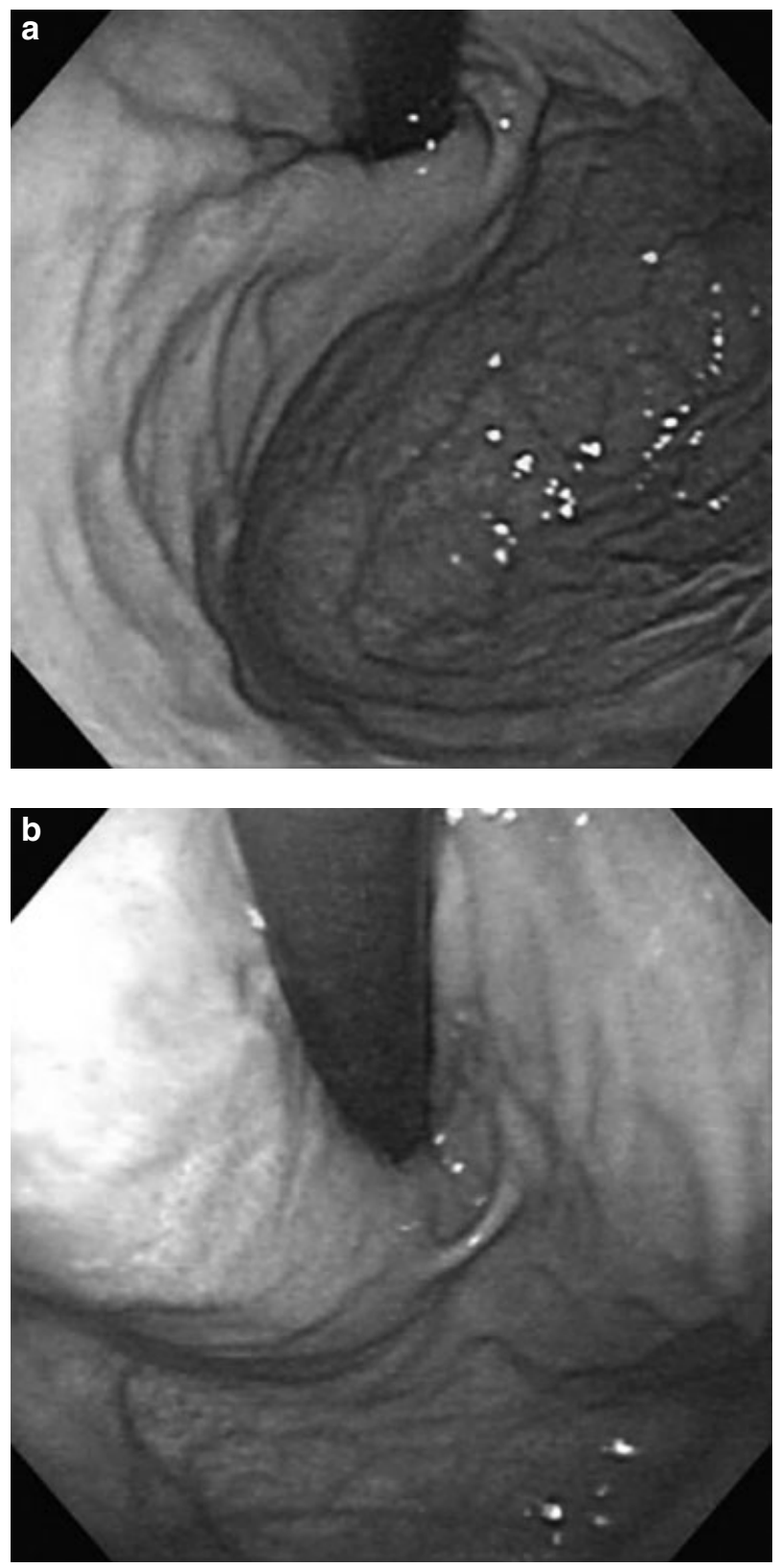

Figure 2 Grade II signified that a fold was present, but slightly less well defined than in Grade I and it opens rarely with respiration and closes promptly; (a) an incomplete fold; (b) a non-contact fold remote to the endoscope.

Table 1 Demographic data and gastroesophageal flap valve grade of study subjects

\begin{tabular}{lcccccc}
\hline & \multicolumn{5}{c}{ Gastroesophageal flap valve } \\
Grade & I & II & III & IV & I + II & III + IV \\
\hline$n(\%)$ & $175(34.6)$ & $193(38.2)$ & $113(22.3)$ & $25(4.9)$ & $368(72.7)$ & $138(27.3)$ \\
Age (mean \pm SD years) & $53.3 \pm 13.3$ & $51.2 \pm 13.3$ & $47.9 \pm 15.3$ & $51.6 \pm 15.8$ & $51.6 \pm 15.8^{\star}$ & $48.5 \pm 13.8^{\star}$ \\
Male : Female & 0.88 & 1.30 & 3.52 & 4.00 & $1.09^{\star}$ & $3.76^{\star}$ \\
BMI (mean \pm SD kg/m ${ }^{2}$ ) & $23.5 \pm 3.5$ & $24.0 \pm 3.3$ & $24.8 \pm 3.1$ & $24.8 \pm 3.5$ & $23.8 \pm 3.4^{\star}$ & $24.8 \pm 3.2^{\star}$ \\
\hline
\end{tabular}

$\star P<0.05$. BMI, body mass index. 


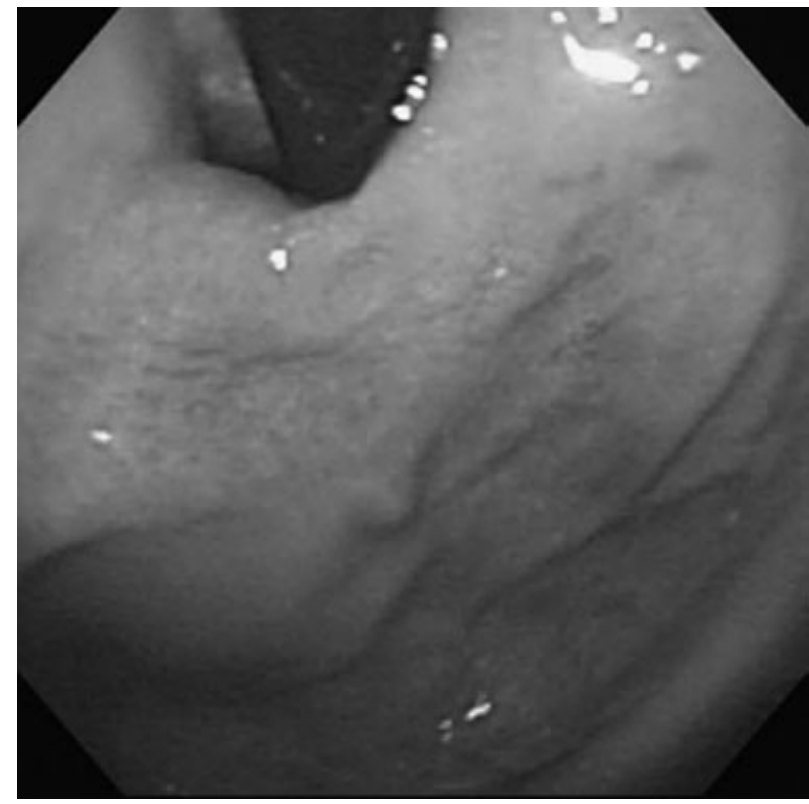

Figure 3 Grade III signified that a fold was not prominent; the endoscope was not gripped tightly by the tissues and often failed to close around the endoscope.

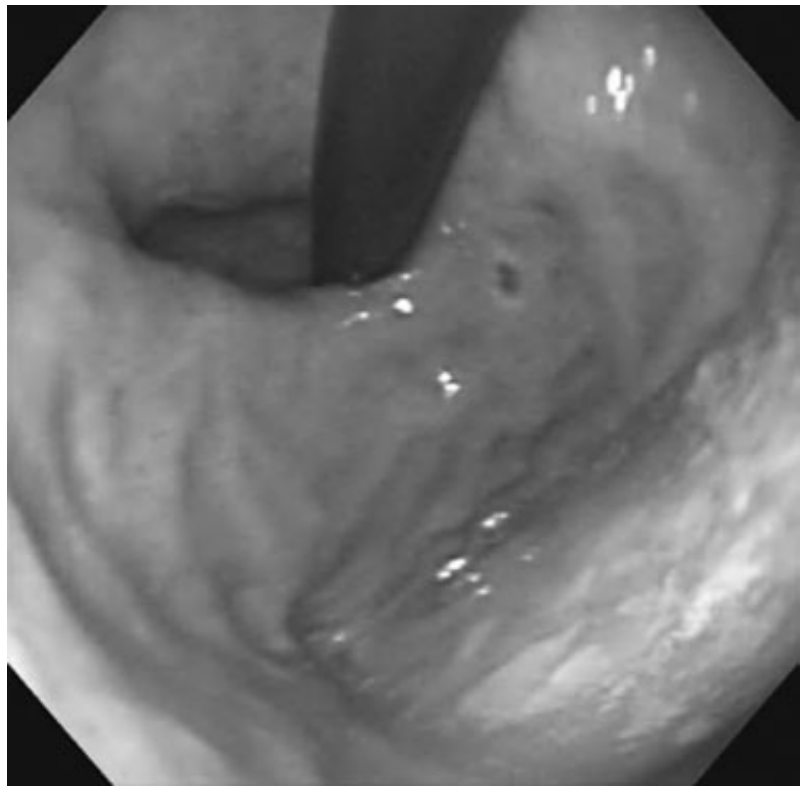

Figure 4 Grade IV signified that there was no fold and that the lumen of the esophagus gaped open, allowing the squamous epithelium to be viewed from below.

Table 2 Correlation of the prevalence of endoscopic esophageal mucosal injury with gastroesophageal flap valve grade

\begin{tabular}{|c|c|c|c|c|c|c|c|}
\hline \multicolumn{8}{|c|}{ Gastroesophageal flap valve grade } \\
\hline & $\mathrm{I}$ & II & III & IV & $\mathrm{I}+\mathrm{II}$ & $\mathrm{III}+\mathrm{IV}$ & $\mathrm{R}$ \\
\hline \multicolumn{8}{|c|}{ Classification of esophageal mucosal injury } \\
\hline $\mathrm{EE}$ & $22(12.6)$ & $44(22.8)$ & $46(40.7)$ & $13(52.0)$ & $66(17.9)$ & $59(42.7)$ & 0.89 \\
\hline $\mathrm{ME}$ & $9(5.1)$ & $19(9.8)$ & $13(11.5)$ & $2(8.0)$ & $28(7.6)$ & $15(10.9)$ & 0.54 \\
\hline NERD & $27(15.4)$ & $33(17.1)$ & $19(16.8)$ & $5(20.0)$ & $60(16.3)$ & $24(17.4)$ & 0.40 \\
\hline $\mathrm{NE}$ & $117(66.9)$ & $97(50.3)$ & $35(31.0)$ & $5(20.0)$ & $214(58.2)$ & $40(29.0)$ & 0.19 \\
\hline
\end{tabular}

$\mathrm{R}$, ratio of abnormal to normal grades of GEFV = case number of grade III + IV/I + II. The chi-squared test with a $4 \times 2$ table and multiple comparative test showed there was a significantly higher proportion of abnormal GEFVs in subjects with EE, ME and NERD than in subjects with NE. EE, erosive esophagitis; ME, minute esophagitis; NE, no esophagitis; NERD, non-erosive reflux disease.

those with normal valves (42.7 vs $17.9 \%, P<0.05)$. In contrast, the prevalence of $\mathrm{NE}$ was inversely correlated to the GEFV grade. NE was present in $58.2 \%$ of patients with normal valves $(66.9 \%$ with grade I), while only $17.9 \%$ of patients with normal valves had EE. Of the patients with abnormal valves, $42.7 \%$ had $\mathrm{EE}$ and only $29.0 \%$ had NE. The ratio of the prevalence of abnormal to normal grade GEFV was highest in EE, followed by ME, NERD and NE. A chi-squared test with a $4 \times 2$ table demonstrated that there were different GEFV grades among the four groups classified by esophageal mucosal injury and symptoms $(P<0.0001)$. Furthermore, a multiple comparative test showed there was a significantly higher proportion of abnormal GEFVs in subjects with EE than in those with NERD and NE $(P=0.007$ and $<0.0001)$; in subjects with $\mathrm{ME}$ as compared with those with $\mathrm{NE}(P=0.003)$; and in subjects with NERD than in those with NE $(P=0.009)$.

Table 3 shows that most of EE in the patients with an abnormal valve were in low-grade esophagitis.

The prevalence of hiatal hernia was $7.7 \%(n=39)$. As shown in Table 4, the prevalence significantly increased with increasing alteration of the GEFV. Up to $80 \%$ of cases of hiatal hernia occurred in patients with abnormal valves.

As shown in Table 5, patients with abnormal valves had a significantly higher incidence of current typical symptoms of GERD at a frequency of once weekly or greater. In addition, among those lacking typical symptoms, patients with abnormal valves had a higher prevalence of atypical or extraesophageal symptoms (45.1 vs $36.0 \%, P<0.05$; the data were calculated in these study populations but are not shown in Tables 1-5); and a 
Table 3 Correlation of grades of erosive esophagitis and gastroesophageal flap valves

\begin{tabular}{|c|c|c|c|c|c|c|}
\hline & \multicolumn{6}{|c|}{ Gastroesophageal flap valve grade } \\
\hline & I & II & III & IV & $\mathrm{I}+\mathrm{II}$ & $\mathrm{III}+\mathrm{IV}$ \\
\hline \multicolumn{7}{|c|}{ Grade of $\mathrm{EE}^{\dagger}$} \\
\hline$n$ & 22 & 44 & 46 & 13 & 66 & 59 \\
\hline A & $17(77.3)$ & $29(65.9)$ & $39(84.8)$ & $8(61.5)$ & $46(69.7)$ & 47 (79.7) \\
\hline B & $4(18.2)$ & $15(34.1)$ & $7(15.2)$ & $3(23.1)$ & $19(28.8)$ & $10(16.9)$ \\
\hline $\mathrm{C}$ & $1(4.5)$ & 0 & 0 & $1(7.7)$ & $1(1.5)$ & $1(1.7)$ \\
\hline $\mathrm{D}$ & 0 & 0 & 0 & $1(7.7)$ & 0 & $1(1.7)$ \\
\hline
\end{tabular}

${ }^{\dagger}$ According to the Los Angeles classification criteria. Data are expressed as $n(\%)$.

Table 4 Prevalence of hiatal hernia in subjects with differing grades of gastroesophageal flap valve

\begin{tabular}{cccccrr}
\hline & \multicolumn{5}{c}{ Gastroesophageal flap valve grade } \\
& I & II & III & IV & I + II & III + IV \\
\hline HH (+) & $2(1.1)$ & $6(3.1)$ & $19(16.8)$ & $12(48)$ & $8(2.2)^{\star}$ & $31(22.5)^{\star}$ \\
HH $(-)$ & $173(98.9)$ & $187(96.9)$ & $94(83.2)$ & $13(52)$ & $360(97.8)^{\star}$ & $107(77.5)^{\star}$ \\
\hline
\end{tabular}

${ }^{\star} P<0.05$. Data are expressed as $n(\%) . \mathrm{HH}$, hiatal hernia, defined as the axial length between the squamocolumnar junction and the gastroesophageal junction $>2 \mathrm{~cm}$.

Table 5 Distribution of symptom groups in patients with differing grades of gastroesophageal flap valve

\begin{tabular}{|c|c|c|c|c|c|c|}
\hline & \multicolumn{6}{|c|}{ Gastroesophageal flap valve grade } \\
\hline & $\mathrm{I}$ & II & III & IV & $\mathrm{I}+\mathrm{II}$ & $\mathrm{III}+\mathrm{IV}$ \\
\hline$n$ & 175 & 193 & 113 & 25 & 368 & 138 \\
\hline \multicolumn{7}{|c|}{ Symptom category } \\
\hline a & $11(6.3)$ & $11(5.7)$ & $13(11.5)$ & $4(16.0)$ & $22(6.0)^{\star}$ & $17(12.3)^{\star}$ \\
\hline $\mathrm{b}$ & $26(14.9)$ & $33(17.1)$ & $18(15.9)$ & $5(20.0)$ & $53(14.4)$ & $19(13.8)$ \\
\hline c & $20(11.4)$ & $28(14.5)$ & $15(13.3)$ & $1(4.0)$ & $53(14.4)$ & $19(13.8)$ \\
\hline d & $10(5.7)$ & $8(4.1)$ & $5(4.4)$ & $1(4.0)$ & $18(4.9)$ & $6(4.3)$ \\
\hline e & $31(17.7)$ & $24(12.2)$ & $15(13.3)$ & $2(8.0)$ & $55(14.9)$ & $17(12.3)$ \\
\hline$f$ & $8(4.6)$ & $5(2.6)$ & $11(9.7)$ & $3(12.0)$ & $13(3.5)^{\star}$ & $14(10.1)^{\star}$ \\
\hline $\mathrm{g}$ & $69(39.4)$ & $84(43.5)$ & $36(31.9)$ & $9(36.0)$ & $144(39.1)$ & $46(33.0)$ \\
\hline$a+b+c$ & $57(32.6)$ & $72(37.3)$ & $46(40.7)$ & $10(40.0)$ & $128(34.8)$ & $55(39.9)$ \\
\hline$d+e+f$ & $49(28.0)$ & $37(19.2)$ & $31(29.4)$ & $6(24.0)$ & $86(23.4)$ & $37(26.8)$ \\
\hline
\end{tabular}

${ }^{\star} P<0.05$. Data are expressed as $n(\%)$.

significantly higher prevalence of current simultaneous atypical and extraesophageal symptoms (17.0 vs $5.4 \%$, $P<0.05$; the data were calculated in these study populations but are not shown in Tables 1-5), in comparison to those with normal valves. Patients with normal valves had a slightly higher incidence of being free of any symptoms.

\section{DISCUSSION}

The present study demonstrates a close association between increasing deformation of the GEFV and endoscopically demonstrated GERD. In contrast to previous studies of patients with symptomatic or severe esophagitis in a Caucasian population, ${ }^{2-4}$ we sought to survey the prevalence of abnormal valves and the distribution of various grades of GEFV in relation to the degree of esophageal injury by simultaneous endoscopy and symptom analysis in Taiwanese subjects presenting for routine health check-ups.

Fujiwara et al. previously described the association of GEFV grade and GERD in a Japanese population. ${ }^{8}$ Our findings clarify the spectrum of GERD in Taiwan and confirm the concept that deformation of the GEFV is closely associated with GERD in Asians, who are traditionally thought to be less predisposed to GERD than Caucasians. ${ }^{15}$ This implies that an altered GEFV is a common pathogenetic factor in GERD, unrelated to ethnicity. 
In the present study, the prevalence of $\mathrm{EE}$, and to a lesser degree NERD, increased with increasing alteration of the GEFV, which is shown by an increasing abnormal to normal valve ratio in NE, NERD, ME and EE. Approximately one-quarter of $\mathrm{ME}$ patients in each group had past typical, current atypical, and extraesophageal symptoms, respectively, implying that abnormal valves are a more sensitive index of esophageal mucosal injury than typical symptoms are. Previous reports have found that abnormal esophageal acid exposure is a better indicator of endoscopic esophagitis than symptoms are. ${ }^{3,16}$ Together with our findings, it is reasonable to believe that the pathology in ME patients is most likely related to acid reflux in a mildest form of EE. Accordingly, it is appropriate to delineate $\mathrm{ME}$ as a group separate from NERD.

Explanations have been proposed towards why NERD patients have a lower ratio of abnormal valves than patients with $\mathrm{EE}$ or ME, but have a ratio comparable to that of NE patients. Patients with NERD may have transient lower esophageal sphincter relaxation; ${ }^{17}$ weakly acidic or non-acidic refluxates; ${ }^{18,19}$ a hypersensitive esophagus; ${ }^{20}$ or other more complex mechanisms. ${ }^{21}$ In contrast, patients with EE are more likely to have a pre-existing structurally defective gastroesophageal junction with incompetent lower esophageal sphincter. ${ }^{22,23}$ In the present study, NERD patients had a prevalence of atypical (55.4\%) and extraesophageal symptoms $(56.6 \%)$, which was much higher than that of patients with $\mathrm{NE}$; in addition, only one-fifth of the patients with typical symptoms but negative endoscopic findings had acid exposure (Lin BR and Liao CC, unpublished observations, 2004). Endoscopic esophagitis has been found to be a better indicator of GERD than typical symptoms in Taiwanese patients. ${ }^{24}$ Thus, in accordance with the study conducted by Contractor et al., ${ }^{4}$ the present study confirmed that GERD patients with endoscopic esophagitis tended to have pre-existing abnormal valves, whose incidence is correlated with severity of esophageal injury.

The use of the GERD symptom questionnaire may have resulted in potential bias, leading to under- or overestimation of the prevalence of NERD, because a wide spectrum of GERD symptoms may depend on different thresholds of visceral sensitivity, ${ }^{16}$ and patients may also have underreported symptoms in the selfadministered questionnaires. ${ }^{24,25}$

It has been shown that EE can accurately predict the presence of acid reflux-related GERD, with modest sensitivity. ${ }^{3}$ Öberg et al. demonstrated that more than half of GERD patients have normal valves, indicating that more than half of GERD patients might actually have NERD. ${ }^{3}$ In the present study, $40 \%$ of patients with GERD had NERD, suggesting that abnormal valves would not be a sensitive predictor of NERD among all GERD patients. In the present study, 29\% of those with abnormal valves had NE and, conversely, $15.7 \%$ of $\mathrm{NE}$ subjects had abnormal valves. This indicates that some subpopulations of NE subjects have no GERD, but could be potentially predisposed to NERD or EE because of abnormal valves. This hypothesis deserves further study.
In the present study, a grade IV valve only predicted $52 \%$ of cases of EE, which is lower than that predicted by esophageal acid exposure (75\%). ${ }^{3}$ Endoscopic grading of the GEFV seems to provide useful information about reflux status, but it is less useful as an indicator of the presence of esophageal mucosal injury. ${ }^{3}$ Ismail et al. hypothesized that the geometry of the GEFV is not the sole factor influencing abnormal acid exposure, but that the loss of the GEFV combined with other factors such as a decrease in LES length and pressure and an increasing prevalence of mechanically defective sphincters, might lead to a higher likelihood of gastroesophageal reflux. ${ }^{26}$ This might be an explanation for why abnormal valves had only a modest sensitivity for lowgrade $\mathrm{EE}$ in our patients.

In accordance with the study by Contractor et al., we found that approximately $13 \%$ of those with grade I valves had EE. ${ }^{4}$ This contrasts with the belief that esophagitis does not occur with a true grade I valve. ${ }^{2,3}$ Furthermore, $29 \%$ of patients with abnormal valves did not have any esophageal mucosal lesions or symptoms comparable to the findings that 29 and $54 \%$ of those with abnormal valves did not have reflux esophagitis or symptoms of GERD, respectively, in other series, ${ }^{3,4}$ but these findings were in contrast to the near-universal association of abnormal valves with esophagitis in Hill's group. ${ }^{2}$ This discrepancy could be explained by two possibilities. First, false-positive patients with minimally affected squamocolumnar junction might be classified as grade A esophagitis. This confounder was avoided in the present study by using well-accepted diagnostic and classification systems. ${ }^{12,13,27,28}$ Abnormal esophageal acid exposure has been documented in $10.6 \%$ of patients with grade I valves. ${ }^{4}$ Second, the GEFV may disappear or appear during respiration or postural change, resulting in false negatives. ${ }^{29}$ We inspected the gastroesophageal junction by retroflexed endoscope and recorded GEFV grade only when the esophagus was steady without contraction or shortening. Therefore, it is conceivable that EE can develop in patients with normal valves. Compatible with the findings by Oberg et al., we demonstrated that the geometry of the valve was a less strong predictor of NERD than EE was. ${ }^{3}$ More well-designed studies are needed to elucidate NERD.

\section{CONCLUSIONS}

Patients with an abnormal GEFV share similar characteristics and risk factors with patients who have EE. The endoscopic grading of the GEFV is highly associated with GERD, and in particular with $\mathrm{EE}$, in subjects undergoing routine endoscopy in Taiwan.

\section{ACKNOWLEDGMENTS}

This study was supported by grants from the National Taiwan University Hospital (NTUH.91S032) and National Science Council (NSC90-2314-B-002-217 and NSC91-2315-B-002-008), Taiwan. 


\section{REFERENCES}

1 Thor KBA, Hill LD, Mercer CD. Reappraisal of the flap valve: In vitro and in vivo mechanisms in the gastroesophageal junction. Acta Chir. Scand. 1987; 153: 25-8.

2 Hill LD, Kozarek RA, Kraemer SJ et al. The gastroesophageal flap valve: In vitro and in vivo observations. Gastrointest. Endosc. 1996; 44: 541-7.

3 Öberg S, Peters JH, DeMeester TR et al. Endoscopic grading of the gastroesophageal valve in patients with symptoms of gastroesophageal reflux disease (GERD). Surg. Endosc. 1999; 13: 1184-8.

4 Contractor QQ, Akhtar SS, Contractor TQ. Endoscopic esophagitis and gastroesophageal flap valve. f. Clin. Gastroenterol. 1999; 28: 233-7.

5 Mahmood Z, McMahon BP, Arfin Q et al. Endocinch therapy for gastro-oesophageal reflux disease: A one year prospective follow up. Gut 2003; 52: 34-9.

6 Mason RJ, DeMeester TR, Lund RJ et al. Nissen fundoplication prevents shortening of the sphincter during gastric distension. Arch. Surg. 1997; 132: 719-24.

7 Jobe BA, Kahrilas PJ, Vernon $\mathrm{AH}$ et al. Endoscopic appraisal of the gastroesophageal valve after antireflux surgery. Am. F. Gastroenterol. 2004; 99: 233-43.

8 Fujiwara $\mathrm{Y}$, Higuchi $\mathrm{K}$, Shiba $\mathrm{M}$ et al. Association between gastroesophageal flap valve, reflux esophagitis, Barrett's epithelium, and atrophic gastritis assessed by endoscopy in Japanese patients. F. Gastroenterol. 2003; 38: 533-9.

9 Richter JE. Typical and atypical presentations of gastroesophageal reflux disease - the role of esophageal testing in the diagnosis and management. Gastroenterol. Clin. North Am. 1996; 25: 75-102.

10 Liebermann-Meffert D, Allgöwer M, Schmid P, Math D, Blum AL. Muscular equivalent of the lower esophageal sphincter. Gastroenterology 1978; 76: 31-8.

11 Boyce HW. Endoscopic definitions of esophagogastric junction regional anatomy. Gastrointest. Endosc. 2000; 51: 586-92.

12 Armstrong D, Bennett JR, Blum AL et al. The endoscopic assessment of esophagitis: A progress report on observer agreement. Gastroenterology 1996; 111: 85-92.

13 Boyce HW. Endoscopic diagnosis and classification or reflux esophagitis: Are we there yet? Gastroenterology 2002; 56: $775-8$.

14 Dent J, Brun J, Fendrick AM et al. On behalf of the Genval Workshop Group. An evidence-based appraisal of reflux disease management: The Genval Workshop Report. Gut 1999; 44 (Suppl. 2): S1-16.

15 Kang JY, Tay HH, Yap I, Guan R, Lim KP, Math MV.
Low frequency of endoscopic esophagitis in Asian subjects. F. Clin. Gastroenterol. 1993; 16: 70-3.

16 Johnson DA, Winters C, Spurling TJ, Chobanian SJ, Cattau Jr EL. Esophageal acid sensitivity in Barrett's esophagus. F. Clin. Gastroenterol. 1987; 9: 23-7.

17 Mittal RK, Holloway RH, Penagini R, Blackshaw LA, Dent J. Transient lower esophageal sphincter relaxation. Gastroenterology 1995; 109: 601-10.

18 Sifrim D, Holloway R, Silny J et al. Acid, non-acid, and gas reflux in patients with gastroesophageal reflux disease during ambulatory 24-hour $\mathrm{pH}$-impedance recordings. Gastroenterology 2001; 120: 1588-98.

19 Shay SS, Johnson LF, Richter JE. Acid rereflux: A review, emphasizing detection by impedance, manometry, and scintigraphy, and the impact on acid clearing pathophysiology as well as interpreting the $\mathrm{pH}$ record. Dig. Dis. Sci. 2003; 48: 1-9.

20 Achem. SR. Endoscopy-negative gastroesophageal reflux disease. The hypersensitive esophagus. Gastroenterol. Clin. North Am. 1999; 28: 893-904.

21 Fass R, Ofman JJ. Gastroesophageal reflux disease should we adopt a new conceptual framework? Am. $\mathcal{F}$. Gastroenterol. 2002; 97: 1901-9.

22 van Herwaarden MA, Samsom M, Smout AJ. Excess gastroesophageal reflux in patients with hiatus hernia is caused by mechanisms other than transient LES relaxations. Gastroenterology 2000; 119: 1439-46.

23 Pandolfino JE, Shi G, Trueworthy B, Kahrilas PJ. Esophagogastric junction opening during relaxation distinguishes nonhernia reflux patients, hernia patients, and normal subjects. Gastroenterology 2003; 125: 1018-24.

24 Lin BR, Wong JM, Yang JC, Wang JT, Lin JT, Wang TH. Limited value of typical gastroesophageal reflux disease symptoms to screen for erosive esophagitis in Taiwanese. F. Formos. Med. Assoc. 2003; 102: 299-304.

25 Carlsson R, Dent J, Bolling-Sternevald E et al. The usefulness of a structured questionnaire in the assessment of symptomatic gastroesophageal reflux disease. Scand. $\mathcal{F}$. Gastroenterol. 1998; 33: 1023-9.

26 Ismail T, Bancewicz J, Barlow J. Yield pressure, anatomy of the cardia and gastro-esophageal reflux. Br. F. Surg. 1995; 82: 943-7.

27 Amstrong D, Monnier P, Nicolet M, Blum AL, Savary M. Endoscopic assessment of esophagitis. Gullet 1991; 1: 63-7.

28 Pandolfino JE, Nimish B, Kahrilas PJ. Comparison of inter-intraobserver consistency for grading of esophagitis by expert and trainee endoscopists. Gastrointest. Endosc. 2003; 56: 639-43.

29 Hill LD, Kozarek RA. The gastroesophageal flap valve. $\mathcal{F}$. Clin. Gastroenterol. 1999; 28: 194-7. 